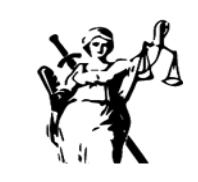

JUSTICIA

ISSN impreso 0124-7441
ISSN digital 2590-4566

\title{
Paros, crisis institucional en américa latina y gobernanza democrática
}

\author{
Strikes, institutional crisis in Latin America and democratic \\ governance
}

\author{
(iD) \\ Diego Fernando Rodríguez Casallas \\ Universidad de Boyacá, Colombia \\ diegombia@hotmail.com \\ Recibido: 12 de diciembre de 2019 / Aceptado: 11 de marzo de 2020 \\ https://doi.org/10.17081/just.25.37.4367
}

\begin{abstract}
Resumen
La crisis de las primeras décadas del presente milenio en Latinoamérica conlleva la necesidad de reflexión para el fortalecimiento institucional que permita legitimar ante la sociedad civil el papel del Estado. Es por ello que la participación ciudadana en la identificación de las problemáticas públicas, diseño e implementación de políticas públicas, monitoreo y evaluación de la misma, adquiere relevancia en el cierre de las brechas existentes entre la sociedad y Estado. La gobernanza democrática es el resultado de la vinculación anteriormente descrita entre sociedad y Estado.

El presente artículo de reflexión es el resultado de las investigaciones realizadas en el proyecto de investigación: "Nominas Paralelas en la Gobernación de Boyacá para el periodo 2005-2015" adelantado en la Universidad de Boyacá y en la Investigación realizada en el desarrollo del Doctorado en Filosofía con énfasis en Ciencias Políticas de la Universidad Autónoma de Nuevo León, en México.
\end{abstract}

Palabras CLAVE: buen gobierno, control social, capital social, gobierno, gobernanza, gobernabilidad, problemática Pública, Política Pública.

\begin{abstract}
The crisis of the first decades of this millennium in Latin America entails the need for reflection for institutional strengthening that allows the role of the State to be legitimized before civil society. That is why citizen participation in the identification of public issues, design and implementation of public policies, monitoring and evaluation of it, becomes relevant in closing the gaps between society and the State. Democratic governance is the result of the aforementioned link between society and the State.
\end{abstract}

This article of reflection is the result of the research carried out in the research project: "Parallel Payrolls in the Government of Boyacá for the period 2005-2015" advanced at the Universidad de Boyaca and in the Research carried out in the development of the Doctorate in Philosophy with emphasis in Political Science of the Universidad Autónoma de Nuevo León, in Mexico.

KEYWORDS: good governance, governance, government, governance, public problems, public policy, social control, social capital.

\section{Como citar:}

Rodríguez Casallas, D. F. (2020). Paros, crisis institucional en américa latina y gobernanza democrática. Justicia, 25(37), 151-166. https://doi.org/10.17081/just.25.37.4367 


\section{INTRODUCCIÓN}

La segunda década del milenio para américa latina ha estado atravesada por crisis institucionales en algunos de los países que la componen; la deslegitimación del Estado, la herencia colonial, las elites gobernantes, la despolitización, los embates económicos y la desarticulación económica del hemisferio sur, han dejado abiertas las puertas a una crisis institucional y política que se exterioriza en manifestaciones, huelgas, paros, alzamientos armados, entre otros. Las practicas del corporativismo, clientelismo político, corrupción y falta de credibilidad en los procesos electorales, han puesto en tela de juicio los sistemas "democráticos" frente a la opinión publica en américa latina. La crisis de gobiernos como los de Chile, Bolivia, Venezuela y los paros acaecidos en el mes de noviembre de 2019 en Colombia, nos lleva a repensar las relaciones Gobierno y Política Pública desde la legitimidad de la actividad del Estado y de la Administración Pública de cara a la sociedad en el cumplimiento de los cometidos Estatales, entendidos como la satisfacción de los requerimientos sociales, en un contexto en el cual sociedad y Estado son lugares cada vez más lejanos.

Por lo anterior, contrarrestar instituciones políticas históricamente cerradas se transforma en el reto para Latinoamérica en la búsqueda de la democratización de sus instituciones, frente a una sociedad que ve cada vez con mayor desconfianza la actividad del Estado. Dicha democratización la entendemos como "gobernanza democrática" que desde una visión simple significaría el acercamiento de la sociedad a la actividad del Estado. El fortalecimiento institucional en las relaciones gobierno y política pública mediante el desarrollo de gobernanza democrática, requiere la construcción de capital social una falencia de la sociedad colombiana y latinoamericana, dicho requerimiento debe ser resuelto mediante un eficaz y permanente ejercicio de control social a la gestión pública, identificando espacios de participación de la sociedad en el diseño, implementación, monitoreo y evaluación de la política pública.

Fenómenos como el corporativismo, el clientelismo político, la corrupción y la apropiación criminal del Estado (Molina Giraldo J. , 2009, pág. 35) han dado evidencias de la apropiación del Estado por Intereses particulares, las elites gobernantes de los países latinoamericanos herederas de las estructuras coloniales, influencian los procesos políticos para proteger sus intereses económicos con un grave consto social en la generalidad de la población. A los datos contenidos en el informe de la Comisión Interamericana de Derechos Humanos CIDH sobre Corrupción y derechos humanos (Comisión Interamericana de Derechos Humanos, 2019), Estándares interamericanos, plantea como frente a los fenómenos de corrupción, se suma la situación de líderes sociales que genera preocupaciones relativas a su seguridad y garantías en el desarrollo de su actividad

Dicho contexto crea un halo de incertidumbre frente a la actividad de los gobiernos latinoamericanos y su rol de garantes de la sociedad civil, el cual se ha hecho más grande con los escándalos de corrupción, que incluso rebasan las fronteras de los países con carteles internacionales que utilizan sus capitales para direccionar la contratación de mega obras con alta rentabilidad para estos emporios, un ejemplo es el caso Odebrecht, (Revista Semana, 2017). El problema de la legalidad en la actividad administrativa estatal ha cedido espacio a la legitimidad, con la necesidad de estructurar canales de comunicación entre la sociedad civil y los gobiernos, como estrategia que permita dinamizar la administración pública generando confianza en su desempeño.

Encendemos la política pública como la manifestación de la voluntad de los gobierno mediante la “designación de los propósitos y programas de las autoridades públicas” (Roth Deubel, 2012, pág. 25), y el gobierno como la manifestación de la voluntad popular en un sistema político democrático mediante elecciones periódicas y libres que determinen la forma como se ha de direccionar la inversión pública o la 
actividad del órgano ejecutor de la política pública. "Cuando el gobierno formula planes generales y decide su implantación es política; cuando establece los medios específicos para su puesta en práctica es Administración. Política es el Gobierno decidiendo, Administración es el Gobierno actuando" (Guerrero Orozco, teoría Administrativa de la Ciencia Política, 1982, pág. 101). Es por lo anterior que la sociedad debe estar presente en la toma de decisión mediante procesos electorales, en la ejecución de dicha decisión y en la verificación de los resultados de la inversión pública.

En consecuencia, de lo anterior, cuando hablamos de las relaciones Gobierno y Política Pública existen dos dimensiones a entender; una de "poder" o decisión y otra de acción o de capacidad institucional en la concreción de la decisión, la gobernanza democrática implica el acercamiento o participación de la sociedad civil en las dos dimensiones.

\section{AMÉRICA LATINA Y GOBERNANZA DEMOCRATICA}

El nuevo milenio y el auge de las telecomunicaciones ha propuesto nuevos escenarios de discusión política, difícilmente controlables las redes sociales y la posibilidad de acceso a la información, han generalizado un malestar que se venía incubando en américa latina de forma similar a como ocurrió en otras latitudes, un ejemplo de ello fue la primavera árabe (Soengas, 2013, pág. 148). La imposibilidad de censura de los escenarios virtuales en los cuales se está construyendo la opinión pública ha abierto debates relativos a la eficaz resolución de los requerimientos sociales de los ciudadanos frente a casos concretos en el sector salud, en relación con la política criminal, escándalos de corrupción etc.

Un fantasma recorre todo el mundo, el fantasma del ciberactivismo. Pero estos fantasmas no se esconden detrás de sábanas blancas: usan la máscara de Guy Fawkes (15701606) popularizada en el cómic $V$ for Vendetta de Moore-Lloyd y levantan en sus puños un dispositivo móvil conectado en red. Las relaciones entre prácticas políticas y redes sociales abren un campo casi infinito de discusión. Si durante décadas los sociólogos se preguntaron sobre los efectos de la televisión en los niños, ahora los politólogos no pueden evitar preguntarse por los efectos de las redes sociales en las movilizaciones sociales. Las preguntas se desplazan como un fotógrafo del National Geographic Magazine: de Túnez a Brasil, de Seattle a El Cairo, de Teherán a Madrid (Scott, 1970, pág. 10).

Casos particulares de problemáticas públicas concretadas en el drama humano individual se muestran a la luz pública en fotos, viñetas y memes que se hacen virales y sensibilizan las comunidades latinoamericanas, que ven en el caso individual la crisis de la institucionalidad. La persona que aparece en redes sociales suplicando por un tratamiento médico evidencia la crisis del sistema de salud, la foto del niño que ve clases en un salón sin techo evidencia la crisis del sector educativo, el puente que se cae antes de ser inaugurado evidencia la corrupción en la contratación. Estos casos individuales han ido tomando forma para evidenciar ante la opinión pública una crisis que es estructural de las democracias latinoamericanas y que tiene sus efectos en las condiciones de vida de los ciudadanos, que empiezan a exigir un papel más amplio en la forma como se toman las decisiones que les afectan y en su control.

Solo en las últimas semanas hubo enfrentamientos en las calles de Bolivia por acusaciones de fraude electoral, en Chile por la desigualdad, en Ecuador por la eliminación de los subsidios a los combustibles y en Haití por la escasez de gasolina y alimentos.

El presidente hondureño, Juan Orlando Hernández, ha enfrentado manifestaciones que exigen su renuncia ante el juicio por narcotráfico a su hermano en Estados Unidos, mien- 
tras el mandatario peruano, Martín Vizcarra, disolvió el Congreso en el marco de una larga crisis política por casos de corrupción.

Marta Lagos, analista política y directora de la encuesta regional Latinobarómetro, cree que este panorama contrasta con el avance de la democracia en América Latina durante la década pasada, antes del estallido de graves crisis políticas en Venezuela y Nicaragua.

Desde Chile, Lagos augura que las manifestaciones en la región van a continuar mientras persista el creciente descontento social con las élites en el poder y la falta de respuesta a demandas de la ciudadanía (Lissardy, 2019).

Los sistemas políticos latinoamericanos son democracias formales caracterizadas por la manipulación de procesos electorales mediante financiamiento de campañas por grupos corporativos, practicas clientelistas y la manipulación del aparato institucional para propósitos particulares y electorales. Sobre el particular, refiere Jiménez Ruiz (2005):

La ciencia política apenas si se ha desembarazado del prejuicio que aparta a la política del dinero, como aquel que aísla a su hija del leproso. No son muchos los textos clásicos que enfrenten la inexorable relación entre la política y el dinero. Al pensar en ejemplos me vienen a la mente, más bien, trabajos literarios. Basten dos novelas de Malraux: Los conquistadores y La condición humana, nos descubren la tortuosa relación entre el dinero y la política. Para financiar al partido, para pagar la revolución es necesario moverse entre los personajes más siniestros de los bajos fondos, mal que bien semejante experiencia termina por viciar a los seres de buena voluntad. Desde una perspectiva ideal se persigue el dinero para no tener que pensar más en él, para asegurar la libertad o de plano liberar a nuestros semejantes de ese ilusorio vínculo social. En la vida, nos cuenta el escritor, el dinero y el poder que lo sigue como hermano inseparable son los que se imponen. El dinero termina convirtiéndose en un fin en sí mismo y las ideas pasan a un demagógico segundo plano. (Jiménez Ruíz , 2005, pág. 6)

En el orden de ideas desarrollado anteriormente, las democracias latinoamericanas son influenciables por los intereses particulares de los grupos de interés que mediante el financiamiento de campañas comprometen a los funcionarios públicos electos para que en sus decisiones privilegien los intereses corporativos, este fenómeno se denomina corporativismo, en palabras del profesor Jesús Molina:

Este corporativismo, hace alusión a la injerencia de organizaciones privadas con intereses particulares, en el direccionamiento del Estado, como así mismo, en muchos casos, en crear correas por parte del Estado para fortalecer su control sobre la sociedad. Aludir al corporativismo, no hace referencia a aquel practicado por Franco o Musollini, donde se crearon pactos con cuerpos de empresarios y trabajadores para el control de la población y el fortalecimiento del Estado (Schitter, 1992). En el momento actual, estará sobre todo dominado el corporativismo por el predominio en la escena política del Estado de representantes del sector financiero, comercial, militar o productivo. Organizados bajo la forma de gremios, grupos o corporaciones privadas, llevarán a que las autoridades de Estado valoren y visibilicen sobre todo sus actuaciones e intereses antes que las del grueso de la sociedad. (Molina Giraldo J. M., 2009, pág. 44).

Campañas políticas opulentas hacen que la ciudadanía ponga en tela de juicio el origen de su financiamiento de dichas empresas electorales o por lo menos genera sospecha sobre el mismo, el musculo económico detrás de las campañas políticas hace que el debate político pase a segundo plano frente a las estrategias de márquetin electoral, legales como ilegales. Ampliando el punto, refiere el profesor Molina: 
Ha llevado la corrupción a que el poder del Estado, quede ampliamente amenazado por redes estatales-privadas locales, regionales, nacionales e internacionales, que saquean los recursos públicamente recaudados o apropian ilegalmente decisiones para favorecer a actores o sectores determinados.

Redes de corrupción de alto y bajo nivel que, mediante prácticas de extorción, sobornos, hurtos, exenciones, amenazas, extracción de información o desplazamientos del sector privado al público estatal, han copado las instituciones Estatales, al punto, que muchos de ellos han entrado en crisis de gobernabilidad por las repercusiones que acompañan dichas prácticas. A nivel internacional, el fenómeno ha merecido cada vez más la atención de los países, al punto de que las cumbres de los organismos multilaterales como la OCDE, OEA o la ONU las han incorporado como un tema de sus agendas, y han emprendido una serie de acciones para hacer que los países que participan de ellas firmen acuerdos contra las prácticas de corrupción, relacionadas con la actuación de sus empresas multinacionales, o bien relacionadas con el lavado de activos (Molina Giraldo J. M., 2009, pág. 50)

Ahora, además del poder económico que da la posibilidad de financiamiento de las campañas electorales para favorecer intereses privados y acceder al poder político, es necesaria una maquinaria electoral que permita la transmutación del poder económico en poder político, esa maquinaria electoral se posibilita mediante el apoyo de actores sociales que pueden o no militar en partidos políticos permanentemente y que se encargan de la realización del proselitismo "político" para captar votos mediante intercambios económicos o prometiendo contraprestaciones futuras una vez se acceda al poder político, dicho fenómeno se denomina clientelismo político.

El clientelismo político es el resultado de una cultura política basada en la informalidad que privilegia intereses particulares, en la cual la construcción del concepto de lo público es precaria, fortalecido por la necesidad económica, pobreza y necesidad de una solución de ocupación laboral en un contexto de desempleo en el cual el principal empleador es el Estado. Sobre el clientelismo define Bobbio:

... el notable, al que estaba reservada de hecho o derecho una relación privilegiada con el poder político, funge como elemento de empalme de éste con la sociedad civil y con los propios clientes a los que les sigue dando protección y ayuda en las relaciones con un poder a menudo distante y hostil, a cambio, ahora, de consensos electorales (Bobbio, 2005, pág. 235).

Para Scott, el clientelismo:

el clientelismo es una forma de intercambio interpersonal, que implica una larga amistad instrumental en la cual un individuo de más status socio - económico (patrón) usa su propia influencia y recursos para proporcionar protección y/o beneficios a una persona de menos status (cliente); a su vez, éste corresponde al patrón al ofrecerte apoyo y asistencia general, incluidos sus servicios personales (Scott, 1970).

De la definición de Scott surgen las relaciones patrón - cliente que determinan las lógicas del sistema clientelista, las cuales se han estructurado en Latinoamérica mediante una larga tradición o herencia colonial de exclusiones (Rodriguez Casallas, 2016, pág. 91) que han configurado una elite gobernante que capturo el poder político en unas relaciones feudales mediante prácticas como el gamonalismo. En el caso colombiano, Fernán González: 
El clientelismo se constituye así como un sistema primitivo y deformado de seguridad social, donde actúan como intermediarios los partidos tradicionales que otorgan bienes y servicios a cambio del apoyo electoral que les permite legitimar su poder en términos de democracia formal, el clientelismo se alimenta del atraso, desempleo, pobreza e insatisfacción de las necesidades básicas de la mayoría de la población y de la necesidad que tienen las clases políticas de una refrendación electoral de su poder por parte de las masas populares (así esta refrendación electoral no logre sobrepasar el 30\% del potencial electoral). El clientelismo sobrevive gracias a la marcada desigualdad de oportunidades para las diferentes clases sociales y al desarrollo desigual de las diversas regiones del país, Así, el clientelismo es la respuesta de una sociedad basada en la desigualdad frente a la igualdad política de tipo formal. (Gonzaléz Gonzaléz, 1997, pág. 98).

La pobreza, la ineficiencia del Estado en la resolución de los requerimientos sociales, la debilidad de las instituciones en las "democracias" latinoamericanas generan la necesidad de una solución de ocupación laboral en las relaciones "patrón - cliente" que van a determinar las lógicas del sistema clientelista, con el político de profesión y las personas que hacen parte de la maquinaria electoral. También refiere el profesor Jesus Molina:

En Colombia, hasta la década de los 90 , son pocas las entidades públicas de los niveles sectoriales y territoriales exentas de prácticas donde los nombramientos administrativos, la adjudicación de contratos, la focalización de beneficiarios y la toma de decisiones no tengan como finalidad el pago de favores, la reproducción de clientelas y el ascenso y enriquecimiento de figuras políticas. A tal punto, la cuestión, que algunos analistas han caracterizado el sistema político colombiano como el ...

....“Tampoco es extraño encontrar situaciones, como en las que, cuando se accede a laborar con una entidad pública, entre los rituales de información de ingreso, se encuentra el de ser enterado, en inducción, a cual sector político pertenecen las directivas y, desde luego, su jefe inmediato; así el neófito y nuevo funcionario o servidor público no haya querido preguntar ni enterarse, todo, para que el funcionario sepa y conozca a quién debe ser leal en la prestación de su colaboración y concurso, en forma más que incondicional". (Molina Giraldo J. M., 2004, pág. 7).

En este orden de ideas el Estado se encuentra capturado por elites e intereses privados que le administran en pro de garantizar sus intereses en oposición al interés general, prolongando las condiciones de pobreza de las personas que son utilizadas dentro de las lógicas patrón - cliente, perpetuando las relaciones de dependencia económica y utilizando el empleo público como mecanismo de contraprestación por la fidelidad o lealtad prestada en la refrendación electoral.

Podemos afirmar que el clientelismo político es el resultado de la aplicación parcial del sistema de carrera administrativa como mecanismo de selección de personal en el sector público, situación que permite utilizar el empleo público como mecanismo de pago de favores en relación a las actividades de refrendación electoral del poder político, dicho sistema de selección de personal es denominado como sistema de botín político.

Sistema de botín político o spoiledsystem: El sistema de botín político corresponde a aquella concepción de que los cargos públicos deben ser desempeñados por personas adeptas al movimiento político que obtenga la victoria electoral o simplemente que detente el poder. Ello implica que los funcionarios no necesariamente serán seleccionados dentro de los más capaces o de mayores méritos, sino que entre aquellos que tengan mayores influencias y mejores padrinos políticos. La estabilidad del funcionario no está garantizada y cualquier cambio político puede ocasionar su remoción. 
El sistema de botín político utiliza el aparato estatal como un medio para lograr el pago de favores electorales y también como instrumento indispensable para asegurar los votos requeridos que garanticen la permanencia del grupo político en el poder.

El origen del nombre botín político se debe precisamente al hecho de que al lograr una victoria electoral se considera que debía otorgarse una recompensa al partido o grupo que resulta victorioso. (Álvarez Collazos, 2009)

Como se mencionó en el artículo: "Nominas paralelas una manifestación del sistema clientelista colombiano", en la segunda mitad del siglo XX, al reducirse el tamaño del Estado, los cargos públicos que con anterioridad se utilizaron como "botín político" en el pago de favores dentro del sistema clientelista colombiano, debió ser reemplazo o complementado por los contratos estatales. La necesidad de los ciudadanos de encontrar empleo y al ser el Estado el principal empleador en Colombia, dieron como resultado un contexto propicio para el sostenimiento del sistema clientelista colombiano con nuevas modalidades de intercambio personal mediante la utilización de la contratación estatal de órdenes de prestación de servicios, como botín (Rodríguez Casallas, 2019, pág. 31).

Guardando las proporciones el fenómeno ha sido generalizado en Latinoamérica, con las connotaciones propias de los diferentes regímenes de los respectivos países. Es por lo anterior, que para los sistemas democráticos en américa latina se hace relevante encontrar canales de comunicación que permitan la articulación de la sociedad y los gobiernos, en el afán de legitimar su actuación, dichos canales pueden ser denominados como gobernanza democrática.

\section{GOBERNANZA DEMOCRÁTICA}

Para el fortalecimiento institucional, las relaciones entre gobierno y política pública han ampliado su espectro de acción a las relaciones sociedad, gobierno y política pública, lo anterior desde el concepto contemporáneo de "gobernanza democrática", el cual tiene como finalidad que desde el estilo de gobernar se legitime la actividad del Estado y la administración pública frente a la sociedad civil. Es por lo anterior que el componente sociedad implica la participación de la comunidad sobre la cual recae la decisión política en el diseño, implementación, monitoreo y evaluación de la política pública. Desde una perspectiva policéntrica Wittingham Munevar, refiere a la gobernanza en los siguientes términos:

\footnotetext{
“Gobernanza es la realización de relaciones políticas entre diversos actores involucrados en el proceso de decidir, ejecutar y evaluar decisiones sobre asuntos de interés público, proceso que puede ser caracterizado como un juego de poder, en el cual competencia y cooperación coexisten como reglas posibles; y que incluye instituciones tanto formales como informales. La forma e interacción entre los diversos actores refleja la calidad del sistema y afecta a cada uno de sus componentes; así como al sistema como totalidad" (Wittingham Munévar, 2011, pág. 222).
}

Ampliando el punto, entendemos la gobernabilidad como capacidad institucional para dar respuesta a los requerimientos o funciones de la organización; $y$, el gobierno es entendido como la manifestación del poder político en un sistema democrático. Ahora las fronteras de la gobernanza se defienden desde los dos conceptos pre citados sumados al Capital social, el cual se entiende como:

“capital social se refiere al potencial de identificación, decisión y realización de acciones colectivas. Un grupo o comunidad con alta capacidad para actuar como un sistema coherente y cohesivo, será sin duda un mejor actor-interlocutor, en las relaciones de gober- 
nanza; una Sociedad Civil fuerte, es crítica en la búsqueda de formas de gobernanza democráticas, a su vez, las formas de gobernanza dominantes pueden fortalecer o debilitar la Sociedad Civil. En sistemas políticos en los que la gobernanza está concentrada y aislada, como en el caso de los regímenes gobernados por elites de baja representación, no hay espacio para la promoción o creación de Capital Social. Finalmente, Capital Social es un concepto que se refiere a una capacidad potencial, mientras que gobernanza es un concepto de acción" (Wittingham Munévar, 2011, pág. 223).

Este último elemento se preocupa por la comprensión del sistema político desde una lógica horizontal que permita establecer relaciones Estado-Gobierno y Sociedad en la legitimación de la actividad de la Administración, es por ello que la sociedad civil desarrolla un papel fundamental en la construcción de gobernanza democrática. Su labor comienza en un primer momento: 1) con la construcción de cultura cívica entendida como insumo previo en el desarrollo de la participación ciudadana por los mecanismos institucionales, en un segundo momento; 2) mediante la apropiación de los mecanismos institucionales del ordenamiento constitucional para la toma de decisiones por medios públicos, y un tercer momento; 3) con el monitoreo y evaluación de la política pública.

\section{ELEMENTOS CONFIGURATIVOS DE LA GOBERNANZA DEMOCRÁTICA DESDE EL CAPITAL SOCIAL}

El concepto de gobernanza democrática refiere a el ejercicio horizontal del poder, en el cual se involucra de forma permanente a la sociedad civil en el proceso de toma de decisiones (Wittingham Munévar, 2011). La gobernanza como forma de gobernar refiere a la capacidad institucional, las estrategias gerenciales y el capital social necesario para apropiar las instancias de toma de decisión. Entendiendo la gobernanza desde la lógica horizontal previamente descrita, la construcción de capital social es requisito previo en la apropiación de las instituciones democráticas y la generación de gobernanza democrática.

Como se mencionó con anterioridad, los fenómenos de corporativismo y clientelismo político son el resultado de una visión a corto plazo en relación a los benéficos que pueden acarrear para la ciudadanía en general, el buen funcionamiento del aparato del estado versus los beneficios individuales de corto plazo que la participación en redes clientelares puede ofrecer a las personas inmersas en dichas lógicas; sumado lo anterior a la necesidad económica que tienen los ciudadanos en condición de pobreza o desempleo.

Es por lo anterior que la construcción de capital social y cultura cívica se muestra como relevantes en la estructuración de un contexto que permita generar una actitud de repudio frente a las practicas que debilitan la democracia, de no ser posible la actitud de los ciudadanos habrá de normalizar las practicas del corporativismo, clientelismo político y corrupción.

\section{La construcción de cultura cívica entendida como insumo previo en el desarrollo de la participación ciudadana por los mecanismos institucionales.}

La construcción de cultura cívica implica la apropiación de la racionalidad pública en la población (Molina Giraldo J. , 2004, pág. 49) dicho ejercicio es una actividad constante de construcción de capital social, mediante la formación para la participación política en un ejercicio democrático de reconocimiento de la pluralidad de intereses, el respeto a la diferencia y demás valores propios del sistema democrático.

En concreto desde los gobiernos escolares, la participación en consejos de juventudes y la formación 
para la democracia impartida en las instituciones educativas, se ha de propender por la apropiación de una actitud de identificación de las problemáticas con contenido público, de los intereses de las fracciones de la población, minorías, grupos étnicos, económicos y los conflictos de intereses (tanto públicos - como privados) que la interacción humana entraña con la posibilidad de su resolución por la vía política o institucional.

Ampliando el punto, además de generarse la actitud de repudio frente a los fenómenos que entorpecen el buen desarrollo de las instituciones democráticas, los ciudadanos deben tener un conocimiento profundo de la estructura del Estado y como se desarrolla el principio de soberanía popular. El rol de partidos políticos, movimientos políticos, grupos representativos y la forma como se determinan las agendas legislativas y las agendas gubernamentales.

La apropiación de los mecanismos institucionales del ordenamiento constitucional para la toma de decisiones por medios públicos.

La apropiación de los mecanismos institucionales del ordenamiento constitucional para la toma de decisiones por medios públicos, refiere al fortalecimiento de la participación ciudadana en las instancias de toma de decisión tanto desde la participación en procesos electorales para la escogencia de cargos públicos de elección popular, hasta la puesta en marcha de los mecanismos de participación ciudadana contemplados en el artículo 103 de la constitución política colombiana.

La participación en los escenarios de discusión política, la militancia en partidos, la elección de autoridades administrativas conforme a las lógicas del voto programático, participación en corporaciones públicas, participación en consejos territoriales de planeación, son mecanismos de apropiación de los escenarios de direccionamiento a la gestión pública, mediante la el diseño e implementación de la política pública.

\section{El monitoreo y evaluación de la política pública.}

El monitoreo y evaluación de la política pública por parte de la sociedad civil da la posibilidad de terminar, re direccionar o redefinir la política pública; ahora el ejercicio de conformación de veedurías ciudadanas permite el monitoreo de planes, programas y proyectos en concreto; los cuales se han de desarrollar en su mayoría mediante la contratación pública, el proceso de vigilancia de la actividad administrativa debe tratar de corregir los riesgo de la contratación (contratos hechos a la medida, direccionamiento de la contratación, monopolio de la contratación, reducción de materiales entre otros).

Ahora un reto para poder hacer el monitoreo de la gestión pública y corroborar que lo prometido a la sociedad civil en los programas de gobierno y posteriormente estructurado en los planes de desarrollo se cumpla, es la forma como se ha de medir dicho cumplimiento. En el anterior orden de ideas los planes de desarrollo deben en la estructuración de la política pública y los diferentes planes programas y proyectos deben incorporar indicadores, metas y escalas de medición que permitan monitorear el avance de la gestión pública.

El modelo integrado de planeación y gestión "MIPG", tiene como pretensión lograr integrar la planeación del desarrollo y la gestión pública para poder monitorear su avance y establecer los correctivos oportunos: 
El Modelo Integrado de Planeación y Gestión -MIPG se define en el Artículo 2.2.22.3.2. del Decreto 1499 del 11 de septiembre de 2017, como un marco de referencia para dirigir, planear, ejecutar, hacer seguimiento, evaluar y controlar la gestión de las entidades y organismos públicos, con el fin de generar resultados que atiendan los planes de desarrollo y resuelvan las necesidades y problemas de los ciudadanos, con integridad y calidad en el servicio (D.A.F.P., 2020).

Desde la sociedad civil la conformación de veedurías ciudadanas permite monitorear la política públi$\mathrm{ca}$, conforme al insumo que generan los modelos y sistemas de control interno, junto con los planes, programas, proyectos y contratos que desarrollan la política pública cuando están estructurados con indicadores y metas que permitan verificar su avance.

\section{GOBERNABILIDAD Y BUEN GOBIERNO}

Como elementos adicionales a la construcción de la gobernanza democrática para la construcción de sistemas políticos democráticos fortalecidos, eficientes y eficaces, se requiere un ambiente de gobernabilidad y elementos técnicos que permitan materializar las decisiones tomadas desde la política (Deutsch, 1976).

En relación a la gobernabilidad desde un sentido estrecho se podría afirmar que es la capacidad institucional o la capacidad de gobernar (Montero Bagatella, 2012, pág. 10), también existen imprecisiones en relación al concepto de gobernabilidad y su diferenciación con el concepto de gobernanza, para el presente escrito entendemos por gobernanza el estilo de un gobierno incluyendo o no a la sociedad civil y por gobernabilidad entendemos la capacidad institucional relativa a los recursos físicos, humanos y financieros que soporten que permitan ejecutar la decisión del órgano político.

Por buen gobierno entendemos la apropiación de los modelos, reglas y principios definidos por la ciencia de la administración pública como los adecuados para el óptimo desarrollo de la actividad administrativa.

en administración pública los principios suelen significar no sólo una "regla", sino también "guía de acción" y "teoría causal". Por cuanto regla, sólo las más generales pueden ser denominadas principios si se considera la amplitud del modo de la declaración. Cuando los principios establecen reglas, éstas suelen tener un carácter normativo y prescriptivo. En administración pública el uso de principio como una "guía de la acción" tiene su base en el sentir generalizado entre los administrativistas de que esa administración debe hacer cosas, y hacerlas bien.4 Una modalidad usual de las guías de acción son aquellas de índole moral llamadas "consejos prudenciales", frecuentemente derivadas de experiencias singulares de funcionarios públicos profesionales que son propuestas como ejemplares (Guerrero Orozco, La formulación de principios en la admnistración pública, 2009, pág. 19)

También pueden interpretarse como modelos gerenciales que permiten estructurar un aparato burocrático eficiente y eficaz en el cumplimiento de los fines para los cuales fue creado.

\section{Problemas de gobernabilidad en américa latina.}

En América latina existen serios problemas de gobernabilidad dado que los recursos para la satisfacción de los requerimientos sociales de los (Araque Calderon, 2008), las crisis institucionales de la segunda mitad 
del siglo XX desgastaron la estructura económica de los Estados latinoamericanos, dictaduras, conflictos internos y el auge del populismo latinoamericano han debilitado la institucionalidad posibilitando que intereses privados hayan cooptado el aparato del Estado.

De manera que algunos planteamientos asumen la crisis del Estado, como agotamiento institucional y principalmente, como crisis de gobernabilidad. Siendo así, tendríamos que cuando el Estado comienza a registrar un incremento substancial y desmesurado de demandas, e igualmente no cuenta con los suficientes recursos económicos e institucionales para dar respuesta eficiente, se producen situaciones de ingobernabilidad que aunado a problemas de gestiones, declive de los proyectos y partidos, relevo generacional no calificado, junto a la presencia de ciertas distorsiones y vicios, terminan produciendo un cuadro crítico del Estado como institución y principal actor del juego político y del entramado institucional (Araque Calderon, 2008, pág. 11)

Las contiendas políticas para llegar al poder del Estado y las prácticas políticas clientelistas, dieron como efecto una función administrativa debilitada que no obedecía a los principios de transparencia, eficacia y eficiencia resquebrajando la moralidad administrativa, con una estructura institucional insuficiente para resolver los requerimientos sociales.

Para finales de la década de los setenta, este modelo de Estado evidencia su agotamiento y entra en crisis, evidenciando sus debilidades entre ellas:

$\gg$ Excesiva burocratización;

$\gg$ Excesiva corrupción;

$\gg$ Excesiva ineficiencia del aparato administrativo;

$\gg$ Presupuestos deficitarios;

$\gg$ Aumento considerable del endeudamiento externo;

$\gg$ Inestabilidad macroeconómica;

$\gg$ Etc. (Araque Calderon, 2008, pág. 13)

Para finales del siglo xx, las prácticas políticas clientelistas utilizaron el aparato del Estado, los cargos públicos y los contratos estatales como mecanismo de pago de favores políticos en un sistema de "botín político", o en otros términos como mecanismo de pago de favores políticos en campaña electoral, tuvieron como resultado que el tamaño del estado en términos de cargos públicos se disparó para poder cumplir con los compromisos adquiridos en época electoral. La consecuencia de la practica descrita fue el déficit fiscal dado que los cargos mencionados debían tener un soporte financiero, lo cual también implico que los gastos de inversión se vieron desplazados a gastos de funcionamiento; resultado de ello fue una planta de personal inflada, difícilmente controlable, en coacciones ineficiente porque fue escogida para pagar favores políticos y no por su capacidad o mérito para el ejercicio del cargo.

Cuando el Estado mediante la administración pública no pudo resolver los requerimientos sociales el Estado perdió legitimidad y cohesión, en casos como el colombiano entraron actores ilegales a resolver dichos requerimientos, desde lo económico hasta la administración de justicia. Las guerrillas, grupos paramilitares e incluso narcotraficantes, se volvieron "ley" en los territorios susceptibles a su dominio, desplazando el poder del Estado y rompiendo el monismo de Estado. 


\section{Problemas en américa latina con el "buen gobierno".}

Como se describió con anterioridad la administración pública entendida como ciencia sugiere una serie de principios, reglas y modelos para que conforme a los acuerdos institucionales realizados en los diferentes países el órgano ejecutor de la política pública funcione bajo los principios de transparencia, eficacia y eficiencia garantizando la prestación de los servicios a cargo del Estado (Guerrero Orozco, La formulación de principios en la admnistración pública, 2009). El buen gobierno hace referencia a la aplicación de los principios, modelos y reglas de la ciencia de la administración publica en la obtención de un aparato burocrático que permita ejecutar de forma eficiente las decisiones tomadas por los gobiernos resultado de los procesos políticos.

Sin embargo, en las democracias latinoamericanas la visión técnica de la administración pública ha cedido paso a la práctica administrativa influenciada por los procesos políticos, un ejemplo de ello es la implementación de sistemas como el de carrera administrativa (Álvarez Collazos, 2009, pág. 89), la cual se ha dificultado en razón a el enquistamiento del sistema clientelista en las prácticas políticas como sucede en el ejemplo colombiano (Molina Giraldo J. M., 2009, pág. 8) que utilizan el empleo público como un mecanismo de contraprestación de favores por apoyo electoral.

Una segunda lógica, para que el poder de estado deje de operar con móviles públicos está dado por las lógicas de corporativismo que al interior de él puedan operar. La igualdad política predicada por el Estado moderno de todos los ciudadanos ser iguales ante la ley, deja de operar, al concederse a determinados sectores de la sociedad más recursos de acceso e influencia para tramitar sus intereses y demandas. Dentro de las mismas instituciones del Estado, se crean estructuras de consulta o de decisión que terminan por dar cabida privilegiada a determinados actores de la sociedad, con los cuales se negocia o consulta en exclusiva o prioritariamente (Meny,1992). Así mismo, que llevan a no ser visto con malos ojos ni se prohíba su presencia e injerencia en la confección de leyes para regular o imponer cargas tributarias a sus propias actuaciones.

Este corporativismo, hace alusión a la injerencia de organizaciones privadas con intereses particulares, en el direccionamiento del Estado, como así mismo, en muchos casos, en crear correas por parte del Estado para fortalecer su control sobre la sociedad. Aludir al corporativismo, no hace referencia a aquel practicado por Franco o Musollini, donde se crearon pactos con cuerpos de empresarios y trabajadores para el control de la población y el fortalecimiento del Estado (Schitter, 1992). En el momento actual, estará sobre todo dominado el corporativismo por el predominio en la escena política del Estado de representantes del sector financiero, comercial, militar o productivo. Organizados bajo la forma de gremios, grupos o corporaciones privadas, llevarán a que las autoridades de Estado valoren y visibilicen sobre todo sus actuaciones e intereses antes que las del grueso de la sociedad. (Molina Giraldo J. M., 2009, pág. 44).

Entendiendo que el empleo público es la forma como se estructura el aparato del Estado, la vinculación de los servidores públicos es fundamental para garantizar: la imparcialidad en la toma de decisiones, el profesionalismo en el desarrollo del cargo y el control de las actuaciones de los servidores (Ramos Acevedo, 2014, pág. 32).

A nivel de Latinoamérica la Carta Iberoamericana de la Función Pública, Aprobada por la V Cumbre Iberoamericana de Ministros de Administración Pública y Reforma del Estado. Santa Cruz de la Sierra, Bolivia, 26-27 de junio de 2003. Respaldada por la XIII Cumbre Iberoamericana de Jefes de Estado y de Gobierno. (Resolución No 11 de la "Declaración de Santa Cruz de Sierra") Bolivia, 14-15 de noviembre de 2003, definió: 
2. La función pública está constituida por el conjunto de arreglos institucionales mediante los que se articulan y gestionan el empleo público y las personas que integran éste, en una realidad nacional determinada. Dichos arreglos comprenden normas, escritas o informales, estructuras, pautas culturales, políticas explícitas o implícitas, procesos, prácticas y actividades diversas cuya finalidad es garantizar un manejo adecuado de los recursos humanos, en el marco de una administración pública profesional y eficaz, al servicio del interés general.

En el ámbito público, las finalidades de un sistema de gestión del empleo y los recursos humanos deben compatibilizar los objetivos de eficacia y eficiencia con los requerimientos de igualdad, mérito e imparcialidad que son propios de administraciones profesionales en contextos democráticos.

3. Son notas básicas de esta noción las siguientes:

a) Se entiende por administración profesional una Administración Pública dirigida y controlada por la política en aplicación del principio democrático, pero no patrimonializada por ésta, lo que exige preservar una esfera de independencia e imparcialidad en su funcionamiento, por razones de interés público.

b) La noción utilizada es compatible con la existencia de diferentes modelos de función pública. Los arreglos institucionales que enmarcan el acceso al empleo público, la carrera de los empleados públicos, las atribuciones de los diferentes actores y otros elementos de la gestión del empleo y los recursos humanos no tienen por qué ser necesariamente los mismos en los distintos entornos nacionales.

c) Los sistemas de función pública pueden incluir uno o más tipos de relación de empleo entre las organizaciones públicas y sus empleados, más o menos próximas al régimen laboral ordinario. La función pública de un país puede albergar relaciones de empleo basadas en un nombramiento o en un contrato, reguladas por el derecho público o por el derecho privado, y cuyas controversias se sustancian ante órganos judiciales especiales 0 ante tribunales comunes

Es por lo anterior, que la implementación parcial del sistema de carrera administrativa en las democracias latinoamericanas, favorece las practicas clientelistas, la corrupción y la apropiación criminal del Estado; lo cual a su vez hace que la administración pública no responda de forma eficaz los requerimientos sociales y genera un clima de ingobernabilidad.

\section{CONCLUSIONES}

Las realidades que hoy por hoy viven las "democracias" en américa latina son el resultado de su cultura política (Almond, Duverger, Mosca, \& R, 1992) entendida como las practicas adoptadas por la población frente a la actividad política como mecanismo de acceso al poder político. La herencia colonial de Latinoamérica genero un sistema político excluyente el cual reservo el acceso al poder político a una elite gobernante, la cual utilizo y manipulo los sistemas electorales para perpetuar su poder económico mediante la influencia sobre los gobiernos de turno.

La tradición, excluyente y elitista de la mayoría de los sistemas políticos latinoamericanos ha distanciado a la sociedad y el Estado, los regímenes tienen apariencia de legalidad, pero se muestran ilegítimos (Rúa Delgado, Carlos, 2013, pág. 88) o en otras palabras el estado fue capturado por intereses privados en detrimento del interés general. 
en la práctica, esa democracia aparece como capturada por grupos de poder que anteponen sus propios intereses a los del conglomerado, generando, de esta manera, bien una captura, o bien una reconfiguración cooptada del Estado colombiano, lo cual afecta directamente la legitimidad política, ya no desde un punto de vista formal, sino material, en tanto que se desnaturaliza el Estado Social de Derecho, dado que, las instituciones que lo componen no van a aparecer con el sentido de satisfacer los principios y derechos consagrados en la parte dogmática de la Constitución, sino que se van a servir del Estado para los propios intereses de quienes han efectuado la captura de las instituciones. Esta captura se ha dado a través de diversas prácticas, siendo el clientelismo una de las más comunes, práctica que se reproduce simbióticamente con la corrupción, lo cual es objeto de análisis líneas adelante. (Rúa Delgado, Carlos, 2013, pág. 88)

Por ello, los beneficios emanados del Estado aplicaron únicamente para la elite gobernante o los grupos económicos que pudieron hacer valer sus intereses con sus intermediarios frente al poder político. La dicotomía entre los principios de la administración Pública y las practicas político administrativas de las "democracias" latinoamericanas ha generado una crisis de legitimidad entorno a su acción.La respuesta a dicha crisis desde la teoría administrativa o una alternativa para el fortalecimiento institucional es la consecución de "gobernanza democrática" entendida como un esfuerzo desde los gobiernos en la vinculación de la sociedad a los procesos de toma de decisión, identificación de la problemática publica, diseño de la política publica, monitoreo y evaluación de la misma. Lo anterior en el afán de legitimar de cara a la sociedad civil la actividad del Estado y la Administración Pública en particular.

De igual forma el fortalecimiento institucional requiere la puesta en práctica de procesos de modernización Estatal que contribuyan a establecer el tamaño adecuado del aparato del Estado; aunados a procesos de implementación del sistema de mérito tanto en la selección de personal como en la evaluación de su desempeño.

\section{Referencias Bibliografíca}

Almond, G., Duverger, M., Mosca, G., \& R, D. (1992). Diez textos básicos de ciencia política. Madrid: Ariel.

Álvarez Collazos, A. (2009). La historia del sistéma de mérito y la aplicación de la carrera admnistrativa en Colombia. Bogota : Escuela Superior de Admnistración Pública .

Araque Calderon, J. (2008). Ingobernabilidad y crisis del Estado en América Latina. Provincia . Universidad de los Andes. Venezuela, 11-33.

Bobbio, N. (2005). Diccionario de Política. Mexico: Siglo Veintiuno.

Centro Latinoamericano de Admnistración para el Desarrollo. (2003). Carta Iberoamericana. Santa Cruz de la Sierra, Bolivia: V Conferencia Iberoamericana de Ministros de Administración Pública y Reforma del Estado.

Comisión Interamericana de Derechos Humanos . (2019). Corrupción y derechos humanos: Estándares interamericanos. San Jose de Costa Rica: $\mathrm{CIDH}$.

Cuadro, M. (2016). Las relaciones en el golfo después de la "primavera árabe" y su impacto en la región. Relaciones internacionales, estrategia y seguridad, 111-135.

D.A.F.P. (23 de 1 de 2020). Alcladia Mayor de Cali. Obtenido de https://www.cali.gov.co/desarrolloinstitucional/publicaciones/143605/modelo-integrado-de-pla

Deutsch, K. W. (1976). Politica y gobierno. Mexico: Fondo de Cultura Económica. 
Gómez Calderón, D. J. (2018). Redes de corrupción política: una revisión para el caso colombiano. Analisis Político, 180-201. doi:http://dx.doi.org/10.15446/anpol.v31n92.71106

Gonzaléz Gonzaléz, F. (1997). Para leer la Politica "Ensayos de historia política Colombiana" Tomo I. Bogota: Universidad Nacional de Colombia .

Guerrero Orozco, O. (1982). teoría Administrativa de la Ciencia Política. Mexico: Universidad Autonoma de Mexico.

Guerrero Orozco, O. (Abril de 2009). La formulación de principios en la admnistración pública. Convergencia, 15-35.

Henao, J. C., \& Isaza Espinosa, C. (2018). Corrupción en colombia "corrupción, politica y sociedad". Bogota: Universidad Externado de Colombia.

Jiménez Ruíz , F. J. (2005). Financiamiento a partidos políticos y teoría de juegos. México: Miguel Ángel Porrúa.

Lissardy, G. (24 de 10 de 2019). BBC. Obtenido de News Mundo: https://www.bbc.com/mundo/noticias-america-latina-50137163

Molina Giraldo , J. (2004). Reconstrucción de la racionalidad pública de la administración estatal. Bogota: Escuela Superior de Admnistración Pública.

Molina Giraldo, J. (2009). Democracia en colombia y poder público ¿Es publico o privado el Estado en Colombia? Bogota: Escuela Superior de Admnistración Pública.

Molina Giraldo, J. M. (2004). Reconstrucción de la Racionalidad Pública de la Administración Estatal. Serie de Documentos. Pensamiento Administrativo Público. Bogota-Colombia: Escuela Superior de Administración Pública - Facultad de Investigaciones .

Molina Giraldo, J. M. (2009). Democracia en Colombia y Poder Público ¿Es público o privado el Estado Colombiano? Bogota : Facultad de Investigaciones, Escuela Superior de Administración Pública .

Montero Bagatella, J. C. (2012). Gobernabilidad: Validez/Invalidez o moda del concepto. Perspectivas Teóricas, 9-23.

Ramos Acevedo, J. (2014). Cátedra de Derecho Administrativo General y Colombiano TOMO I. Bogota: Ibañéz.

Revista Semana. (24 de 1 de 2017). Obtenido de Lo que debe saber del escándalo de corrupción de Odebrecht: https://www.semana.com/nacion/articulo/odebrecht-escandalo-de-corrupcion/513209

Rodríguez Casallas, D. (2019). Nominas paralelas una manifestación del sistema clientelista colombiano. Vía Iuris(27), 163-205. Obtenido de https://revistas.libertadores.edu.co/index.php/Vialuris/article/ view/900

Rodriguez Casallas, D. F. (2016). La encrucijada de la descentralización en Colombia. Justicia, Sociedad y Derecho, 87-113. doi: https://doi.org/10.24267/25009389.156

Roth Deubel, A.-N. (2012). políticas Públicas. Bogota: Aurora.

Rúa Delgado, Carlos. (2013). La legitimidad en el ejercicio del poder político en el estado social de derecho una revisión desde el caso colombiano. Ius et Praxis vol.19 no.2 Talca 2013, 85-122. doi:http://dx.doi. org/10.4067/S0718-00122013000200004

Scott, J. (1970). Patron Client Politics and Political Change. Los Angeles- Estados Unidos : 66th. Annual Meeting of the American Political Sience Associatión.

Soengas, X. (2013). El papel de Internet y de las redes sociales en las revueltas árabes: una alternativa a la censura de la prensa oficial. Comunicar, 147-155. doi:http://dx.doi.org/10.3916/C41-2013-14

Velasco, J. D., Ducan, G., \& Lopera, F. (Septiembre de 2018). Oligarquía, poder político y narcotráfico en Colombia: los casos de Medellín, Santa Marta y Muzo. Colombia Internacional. doi:http://dx.doi. 
org/10.7440/colombiaint95.2018.07

Wittingham Munévar, M. (10 de 19 de 2011). ¿Qué es la gobernanza y para qué sirve? Analisis Internacional, 1(2), 219 - 235. Obtenido de https://revistas.utadeo.edu.co/index.php/RAl/article/view/24

Zurbriggen, C. (2011). Gobernanza: una mirada desde América Latina. Perfiles latinoamericanos. Obtenido de http://www.scielo.org.mx/scielo.php?script=sci_arttext\&pid=S0188-76532011000200002 